\title{
Toward Next Generation Plasmonic Nanopore Slit Platform with a 10 nm Slit-Width
}

Seong Soo Choi ${ }^{1,}{ }^{*}$, Byung Seong Bae ${ }^{2}$, Kyoung Jin Kim ${ }^{1}$, Myoung Jin Park ${ }^{1}$, Yong Min Lee ${ }^{1}$, Hyun Tae Kim ${ }^{3}$, Soo Bong $\mathrm{Choi}^{3}$

1. Research Center for Nano-Bio Science, SunMoon University, Tangjung-Myun Sunmoon-Ro 22170, Ahsan, Korea; E-Mails: sscphy2010@gmail.com; kjkim@sunmoon.ac.kr; mipark.park@gmail.com; ymlee@sunmoon.ac.kr

2. School of Electronics and Display Engineering, Hoseo University, Ahsan, South Korea; E-Mail: bsbae3@hoseo.edu

3. Department of Physics, Incheon National University, Incheon, South Korea; E-Mails: htkim27@inu.ac.kr; sbchoi@gmail.com

* Correspondence: Seong Soo Choi; E-Mail: sscphy2010@gmail.com

Academic Editor: Georgia Paraskevi Nikoleli

Special Issue: Nanosensors: Recent Advances and Future Trends

Recent Progress in Materials

2021, volume 3, issue 1

doi:10.21926/rpm.2101004
Received: December 22, 2020

Accepted: January 26, 2021

Published: February 05, 2021

\begin{abstract}
We fabricated various nanoaperture plasmonic platforms for single-molecule detection. We fabricated nanoapertures like nanopores on a pyramid and nanoslits on an Au flat membrane using a Ga ion focused ion beam drilling technique, followed by irradiating with a high energy electron beam, dependent on the electron beam current density to obtain nanoapertures with a few nanometer sizes (circular nanopore, nanoslit pores). We examined their optical characteristics with varying aperture sizes and sample thicknesses. We obtained broad emission spectra in the visible and infrared region from the $(7 \times 7)$ slit array and a sharp, strong infrared emission peak from the Au nanoparticle on the substrate. The fabricated Au platform with $\sim 10 \mathrm{~nm}$ nanometer opening can be employed as a single-molecule sensor and an infrared thermal emission device.
\end{abstract}

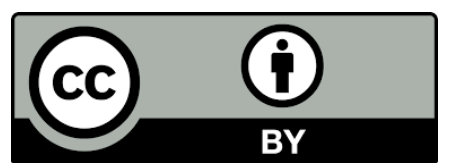

(C) 2021 by the author. This is an open access article distributed under the conditions of the Creative Commons by Attribution License, which permits unrestricted use, distribution, and reproduction in any medium or format, provided the original work is correctly cited. 


\section{Keywords}

Au nanoaperture; intraband; interband emission; surface plasmon; transmission electron microscopy; focused ion beam technique

\section{Introduction}

There have been tremendous interests in nanoapertures for single-molecule detection since DNA translocation and analysis via the natural nanopore (alpha-hemolysin nanopore) was carried out [1]. However, due to the negligible optical intensity through the tiny nanoaperture, plasmonic optical enhancement is required either by plasmonic hot spot or pattern-grooving and periodic arrays [27]. Recently, a SiN nanopore surrounded with Au nanowell with $100 \mathrm{~nm}$ diameter was fabricated [8] due to the difficulties in fabrication of the nanometer-sized metallic apertures.

The Au nanopore formation, using a diffusion technique, with a diameter of $\sim 5 \mathrm{~nm}$ was also reported [3-7] and using a drilling technique with high-energy electron beam irradiation [9]. The fabricated Au nanopore slit array with $\sim 10 \mathrm{~nm}$ slit width can be utilized as a portable optical detection device for single-molecule analysis.

The fabrication of the nanoapertures with periodic groove patterns was reported to enhance the optical intensity through the tiny aperture $[3-6,9]$. The pyramidal probe has been found to provide excellent light confinement inside a $\mathrm{V}$-shaped cavity and enhanced optical throughput via cavity resonance and nanofocusing [3, 8-11]. Hence, the metallic nanostructure with an inverted pyramidal pit array would provide the immensely enhanced optical intensity for surface plasmonic Raman spectroscopy (SERS) [12]. We previously reported the SERS intensity enhancement using biolinker 1,2-Di(4-pyridyl)ethylene on the nanopatterned pyramidal probe [9].

Circular-type nanopore formation on pyramidal apices using focused $\mathrm{Ga}$ ion beam milling techniques followed by electron beam irradiations under high energy electron beam techniques has also been reported [3-7]. Upon high energy $\mathrm{Ga}$ ion impingement on the sample surface, atomic mixing occurs in the melted region within picoseconds, the ions diffuse, followed by the nanopore formation. This phenomenon can be ascribed to the thermal spike model $[7,13,14]$. During high energy ion beam impingements, the pore closing would occur due to the formation of a stressed viscous surface layer from high thermal temperature and atomic transport to the pore or mobile surface atom diffusion to the pore.

Fabrication of a circular-type nanopore with its diameter ranging from $\sim 3 \mathrm{~nm}$ to $\sim 10 \mathrm{~nm}$ using various surface modifications was reported $[3,4,6-7,9]$. Ostwald ripening and spinodal decomposition on the diffused membrane were also observed under high-intensity electron beam irradiation [9]. It is generally understood that, for the samples with their aperture diameter smaller than the aperture thickness, the $\mathrm{Au}$ and $\mathrm{C}$ atoms diffuse inside the aperture, and it shrinks and forms the nanopore diffused with $A u$ atoms and $C$ atoms [4-7]. However, when the aperture diameter is larger than the aperture thickness, diffusion of $A u$ and $C$ atoms never occurs for TEM electron beam treatments. On the contrary, for the electron beam irradiations using FESEM, the aperture always shrinks regardless of the ratio of the aperture diameter to the aperture thickness. It may be attributed to the fast solid-state diffusion under very high electron beam probe current density of 
$1 \mathrm{nA} / \mathrm{nm}^{2}$ for FESEM and to the liquid state equilibrium under electron beam irradiations with its current density ranging from $\sim 10^{2} \mathrm{pA} / \mathrm{cm}^{2}$ to a few $\mathrm{pA} / \mathrm{cm}^{2}$ using TEM [4-7].

Growth of Au nanoparticles in nature was reported to have five body structures; the tetrahedron, the cube, the octahedron, the pentagonal dodecahedron, the icosahedron, as proposed by theory of five geometrical body structures in nature by Greek Philosopher, Plato. The faces of Plato's polyhedral are triangles, squares, and pentagons. Later, Kepler was inspired by observing the growth and the shape of pomegranate seeds and constructed the highly symmetric rhombic polyhedral [15]. The vacuum-deposited gold film consists of nanoparticles and multiple twin particle clusters with various shapes and sizes, of decahedron shape and icosahedron shape such as multiple twin particles (MTP) with a decahedron shape and an icosahedron shape [16-17]. Irregular variation of melting temperature for Au nanoparticles would present experimental difficulties for reproducible results $[18,19]$. Au clusters with magic numbers are stable with higher melting temperatures than those of the usual nanoparticles [19-21].

During the electron beam irradiation on a thick specimen, a rise in its local temperature can be easily achieved, for high-energy electron beam irradiation, using FESEM or TEM. Widening or the closing (shrinking) may occur depending upon the viscosity of the heated membrane and the surface tension force, and the vapor pressure of the material $[3-7,22,23]$. Also, because graphene is a 2D sheet of carbon atoms and the carbon-graphite filter membrane consists of a periodic layer-by-layer slit structure with $\sim 5 \mathrm{~nm}$ gap [24, 25], the Au nanopore slit array containing carbon atoms could be an excellent candidate for the plasmonic nanoaperture platform. For nanoscale double slits, the surface plasmonic wave from the nanoslits can provide the periodic interference phenomena for the TM wave between the nanoscale slits, which reduces or enhances the intensity of the far-field [26-28]. With proper control of the circular aperture pitch and the nanoscale slits separation gap, the optical intensity can be enhanced.

Fabrication of plasmonic nanopore on a pyramid and nanoscale double slits is previously investigated [5-7, 29-31]. It is reported that the light transmission through a conical type aperture is dependent on the polarization and aperture size for $k a<<1$, where $k$ is the wave vector while $a$ is the radius of the circular aperture $[32,33]$. Lord Raleigh developed the theory of diffraction by a small nanoparticle and found that the far-field optical emission profile cannot distinguish its shape because light cannot recognize the particle with a size much smaller than the wavelength [34]. This theory can be applied for the nanoaperture with its size much smaller than the wavelength, combining the Babinet principle [35]. Besides, with decreasing aperture size, the diffracted angle increases, and the intensity profile becomes broader even with a backward scattering up to $40 \%$ for the conical aperture diameter of $60 \mathrm{~nm}$ [32]. Furthermore, for the conical aperture diameter of $60 \mathrm{~nm}$ and P-polarized beam, backward scattering of the incident beam from the aperture is theoretically presented using quasi-multiple dipole approximation and can be attributed to a Poynting vector flow along the pyramidal surface of the aperture on the pyramidal apex [33].

Surface plasmon (SPP) mediated intraband emission, and the SPP-coupled transmission peaks with incoming waves dependent on the size of the nanoaperture and the sample thickness are reported [36]. The intraband optical peak at $500 \mathrm{~nm}$ is shown on the $180 \mathrm{~nm}$ thick Au films with and even without a single hole with $\sim 250 \mathrm{~nm}$ diameter. Visible emissions are generated from the interband transitions of the $d$-band electrons into the conduction band followed by radiative recombination, and the strong infrared emission has resulted from the intraband transitions mediated by the confined fields near metal nanostructures (localized surface plasmons) [37]. 
Localized surface plasmon generates an emission peak in the infrared region due to the intraband transitions between conduction band states $[37,38]$. The spatial confinement and coupling of the near-field results in an increase in the contribution of higher-order transition moments such as the electric quadrupole and octupole. Hence, the radiative intraband transitions in the conduction band can be allowed to cause the near-infrared emission observation of the nanostructures.

The strongly confined fields near gold nanostructures like a nanoslit array with a tiny 10 nm opening width can also generate emission peaks in the infrared region due to the intraband transitions between conduction band states. The strong emission spectra in the visible range from the tiny apertures with various shapes can be utilized for single-molecule detection and analysis. Additionally, near-infrared emission, generated by nanoslits, can also be utilized for the far-field emitters and possible nearfield thermal cooling [39, 40]. In this report, we will demonstrate the fabrication of various nanoaperture platforms with a circular-type aperture and a nanoslit-type array and their optical characterizations.

\section{Materials and Methods}

Two types of Au nanoaperture platforms will be designed and fabricated: Nano-aperture array on the pyramid and flat membrane. First, we carried out the fabrication of nanometric size aperture arrays on top of oxide pyramids using conventional Si microfabrication techniques as in Figure 1(a)1(f). Additionally, TEM grid samples with $(100 \mu \mathrm{m} \times 100 \mu \mathrm{m}) \mathrm{SiN}$ membranes were also purchased from TEMwindows Company (www.temwindows.com), followed by the physical vapor deposition of $\mathrm{Au}$ thin films and dry etching of the supporting SiN film, depending upon the experimental conditions. After bulk Si etching on the backside of the Si wafer using TMAH solution, a (10 x 10) oxide pyramidal array is presented in Figure $1(\mathrm{~g})$, and a side view of the single oxide pyramid is given in Figure 1(h). A circular oxide aperture on top of the pyramid is shown, occurring due to stressdependent oxide growth on the pyramidal apex and slow isotropic etching of the $\mathrm{SiO}_{2}$ as in Figure 1(i). Then, deposition of $200 \mathrm{~nm}$ Au thin film was performed using a thermal-deposition system. It was followed by $30 \mathrm{keV}$ Focused Ga Ion Beam (FIB) drilling with the Focused Ion beam instrument (FEI Helios NanoLab Dual Beam system) and high energy electron beam irradiations using Field Emission Scanning Electron beam Microscopy (FESEM) and Transmission Electron beam Microscopy (TEM). TEM (JEM-2010 and JEM-3011 HR), FESEM (JSM 6400) were utilized at National Nation Fabrication Center (NNFC) in Daejeon, Korea. The optical spectra in the visible range were obtained using the Nikon Optical Eclipse Ti-U microscope with Princeton Instruments spectrophotometer (Acton SpectroPro 2300i, $150 \mathrm{~g} / \mathrm{mm}$ ). Besides, a solid-state Nd:YAG laser system with a wavelength of $532 \mathrm{~nm}$ as a light source and a silicon photosensor with a $15 \mathrm{~mm}$ cone attenuated F-filter (spectral range: $400 \mathrm{~nm}$ to $\sim 1064 \mathrm{~nm}$ ) for photodetection using a Witec SNOM instrument were used in the experimental setup. The minimum detection limit is of the order of $1 \mathrm{nW}\left(\sim 8.0 \times 10^{-10} \mathrm{~W}\right)$. The detailed schematics of the optical measurements are provided in the [Figure S1]. 


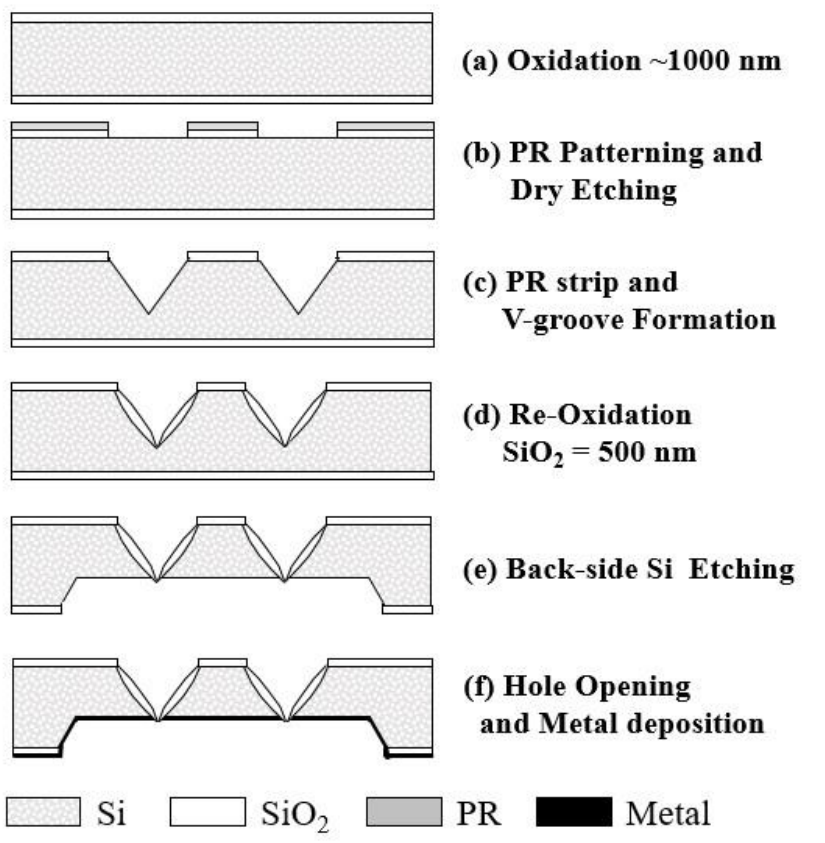

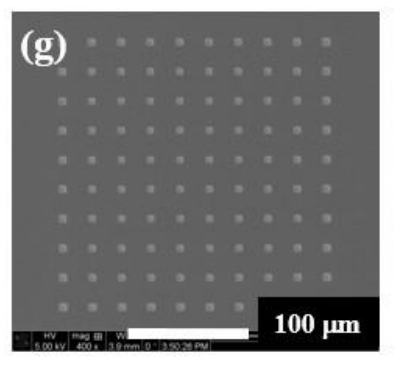
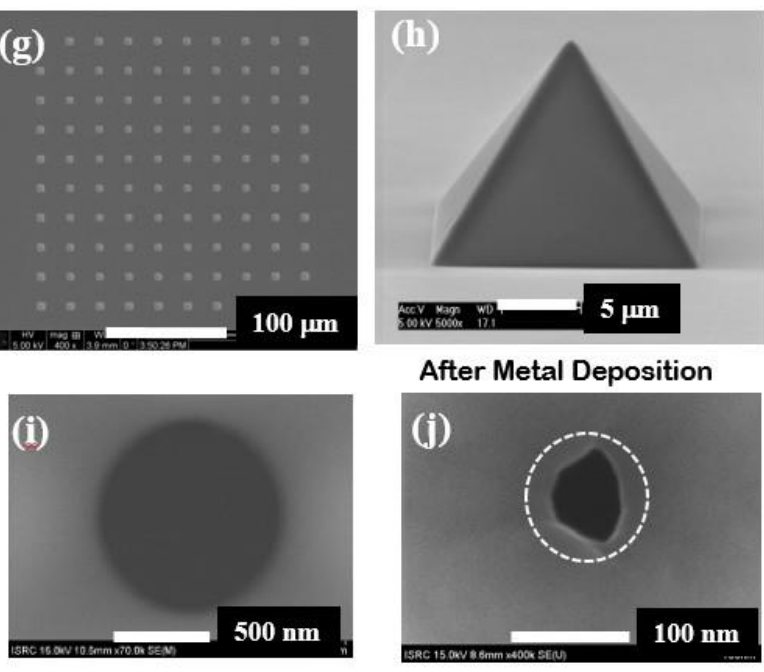

Figure 1 Fabrication schematics of the nano-apertures: Figure 1 (a)-(f). Figure $1(\mathrm{~g})$ shows the $(10 \times 10)$ pyramidal array, and a FESEM image of the side view of the single pyramid is shown in Figure 1(h). FESEM images of the circular hole at the top of the pyramid after the TMAH bulk etching are presented in Figure 1(i), and the nanoaperture after $\mathrm{Au}$ thermal deposition is shown in Figure 1(j).

\section{Results}

We have fabricated the nanoapertures on a flat membrane and a pyramid, deposited by Au thin film, followed by $30 \mathrm{keV}$ Ga ion focused ion beam milling. Fabrication of a circular aperture, with its diameter of $100 \mathrm{~nm}$ or less, is rather difficult due to an unstable focused ion beam during milling processing. Drilling the circular aperture with a $100 \mathrm{~nm}$ diameter or smaller would result in an elliptical aperture. To reduce the aperture size down to a few nanometer diameter after FIB drilling, we carried out two-step electron beam irradiations: (i) an electron beam irradiation of $\sim 1 \mathrm{nA}$, at 2 keV using FESEM, (ii) electron beam irradiations with a current density ranging from $\sim 10^{0}$ to $10^{2}$ at $\sim 10^{2} \mathrm{keV}$ using TEM microscope. In this report, circular apertures with $\sim 200 \mathrm{~nm}$ or greater diameter are initially fabricated on the $200 \mathrm{~nm}$ thick Au film. Then, to reduce the size of the circular-type Au aperture down to $\sim 50 \mathrm{~nm}$ diameter, a $1.4 \mathrm{nA}$ electron beam irradiation at $2 \mathrm{keV}$ for $10 \mathrm{sec}$ was employed using the field emission scanning electron beam instrument installed at Dual Beam Helio (FEI), followed by the high energy electron beam irradiation by using TEM. We also fabricated the nanoslit array with its opening width ranging from $100 \mathrm{~nm}$ to $\sim 10 \mathrm{~nm}$ using $30 \mathrm{keV} \mathrm{Ga} \mathrm{FIB}$. The plasmonic effect from the nanoslit array is well known [29-31]. Nanoslit fabrication with an opening less than $50 \mathrm{~nm}$ is much easier than the circular-type aperture with a diameter of $50 \mathrm{~nm}$ or less.

\subsection{Pore Formation Process Mechanism: Influence of the High Energy Electron Beam Irradiation}

We investigated pore formation on the FIB drilled Au aperture under the influence of a high energy electron beam irradiation using TEM (JEM-2010, JEM-3011 HR). Figure 2(a) shows a nanopore with a diameter of $55.75 \mathrm{~nm}$ on the gold diffused membrane mixed with carbon atoms 
after the 2 keV FESEM electron beam irradiation. For the aperture, with a diameter greater than its thickness, it would not shrink even with high energy electron beam irradiation at $300 \mathrm{keV}$ TEM. However, for electron beam irradiation using FESEM, Au atoms on the surface diffuse into the aperture, then form the nanopore on the diffused $A u$ membrane mixed with carbon atoms. Therefore, we applied a two-step process for the pore formation for FIB drilled Au aperture with a $279.5 \mathrm{~nm}$ diameter.
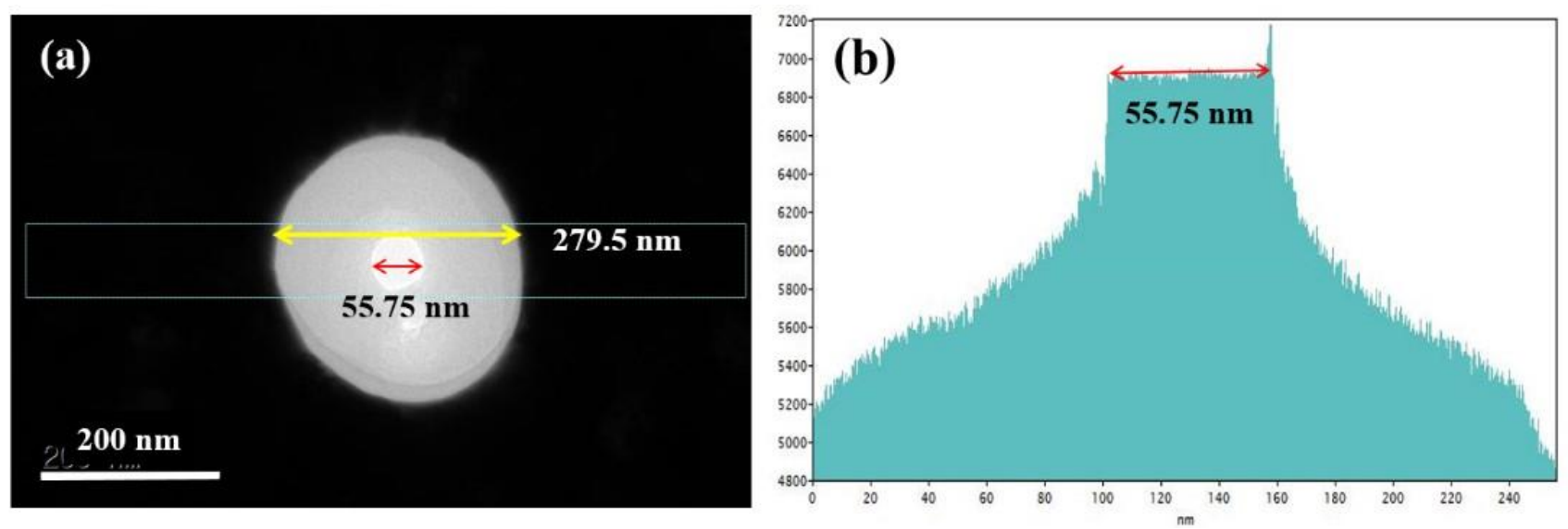

Figure $2 \mathrm{~A} \sim 279.5 \mathrm{~nm}$ diameter circle was initially drilled on a $200 \mathrm{~nm}$ thick Au flat film by $30 \mathrm{keV}$ Ga ion beam followed by high energy electron beam irradiation at $2 \mathrm{keV}, 1.4$ nA FESEM electron beam irradiation for $10 \mathrm{sec}$. A TEM image of the $55.75 \mathrm{~nm}$ diameter nanopore on the Au diffused membrane 2(a). An electron beam intensity profile at the electron detector displays the $55.75 \mathrm{~nm}$ diameter of the formed nanopore on the diffused Au membrane mixed with carbon atoms 2(b).

\subsubsection{Pore Formation on the Aperture with a Diameter Bigger than the Aperture Thickness}

Figure 3 exhibits the pore shrinkage under successive electron beam irradiations for $50 \mathrm{~min}$. For the $1^{\text {st }}$ and $2^{\text {nd }}$ electron beam irradiations for $10 \mathrm{~min}$ and $20 \mathrm{~min}$, respectively, the pore shrinks from $55.75 \mathrm{~nm}$ to $30.79 \mathrm{~nm}$, then to $20.97 \mathrm{~nm}$. However, the pore shrinking rate becomes slower; for the $3^{\text {rd }}, 4^{\text {th }}$, and $5^{\text {th }} 10$ min-electron beam irradiation, from $20.97 \mathrm{~nm}$ to $7.96 \mathrm{~nm}$, to $5.79 \mathrm{~nm}$, and down to $4.20 \mathrm{~nm}$, respectively. The pore shrinking rate at 5 th electron beam irradiation is $\sim 0.159$ $\mathrm{nm} /$ minute. 


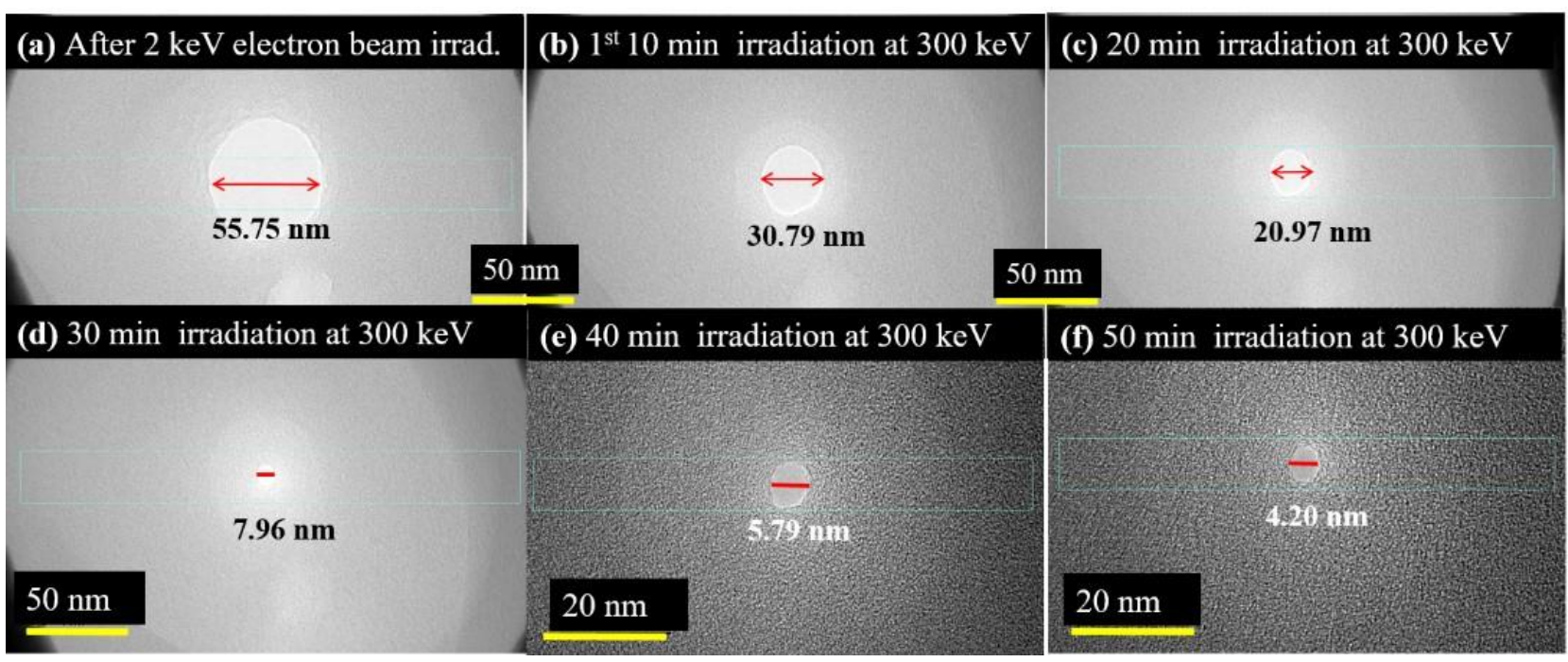

Figure 3 Successive electron beam irradiations with a 10 min-interval performed under $3 \mathrm{pA} / \mathrm{cm}^{2}$ low current density of high energy electron beam irradiation at $300 \mathrm{keV}$ TEM (JEM-3011 HR). A TEM image of a $55.75 \mathrm{~nm}$ diameter nanopore on the Au-C diffused membrane is presented, Fig. 3(a). A nanopore with a diameter of $55.75 \mathrm{~nm}$ was reduced to a smaller diameter nanopore of $30.79 \mathrm{~nm}, 20.97 \mathrm{~nm}, 7.96 \mathrm{~nm}, 5.79 \mathrm{~nm}$, and $4.20 \mathrm{~nm}$ for $10 \mathrm{~min}, 20 \mathrm{~min}, 30 \mathrm{~min}, 40 \mathrm{~min}$, and $50 \mathrm{~min}$, respectively.

\subsubsection{Pore Formation on the Aperture with a Diameter Smaller than the Aperture Thickness}

Figure 4 presents the TEM images under the high energy electron beam irradiation on the FIB drilled Au aperture using a $200 \mathrm{keV}$ TEM. For a designed diameter of $50 \mathrm{~nm}$, we obtained an eggshaped aperture $(56.2 \mathrm{~nm} \times 33.1 \mathrm{~nm})$ due to the straggling of the focused Ga ion beam drilling process. Also, a pore of dimensions ( $22.2 \mathrm{~nm} \times 25.7 \mathrm{~nm}$ ) was formed on the Au-C mixed membrane inside a drilled $\mathrm{Au}(56.2 \mathrm{~nm} \times 33.1 \mathrm{~nm})$ aperture. Due to the thermal spike rise during a $30 \mathrm{keV}$ FIB drilling process, $\mathrm{Au}$ atoms and $\mathrm{C}$ atoms diffuse simultaneously and form the thin membrane mixed with gold and carbon atoms, such that several Au particles and clusters on the Au-C diffused membrane form. A big Au particle ( $10 \mathrm{~nm}$ diameter size of one particle on the left) (dashed red line) and another one on the right are shown in Figure 4(a). After 1st electron beam irradiation with $60.8 \mathrm{pA}$ for $5 \mathrm{~min}$, the $(22.2 \mathrm{~nm} \times 25.7 \mathrm{~nm})$ pore reduced to $(8.3 \mathrm{~nm} \times 15.3 \mathrm{~nm})$, Figure $4(\mathrm{~b})$. After the $2 \mathrm{nd} 99.8 \mathrm{pA}$ irradiation at $200 \mathrm{keV}$, the pore closed completely, and the diffusion of Au particles is seen clearly, Figure 4(c). After the 3rd 152.8 pA electron beam irradiation for 5 min, the diffused Au particle (13.5 $\mathrm{nm}$ diameter, inside the red dashed circle) became bigger than the one before electron beam irradiation, Figure $4(\mathrm{a})$. The diameter of the Au particle ( $10 \mathrm{~nm})$ before electron beam irradiation in Figure 4(a) became slightly bigger; the diameter of the Au particle was $13.5 \mathrm{~nm}$ as in Figure 4(d). The diffused membrane became thinner, the small particles became smaller, and the big particles became bigger. This phenomenon is because of Ostwald ripening. Please note that the large circular type particle (left side in Figure 4(a) was moved to the right and changed to an ellipsoidal shape particle (inside the dashed red inside in Figure 4(d)). 

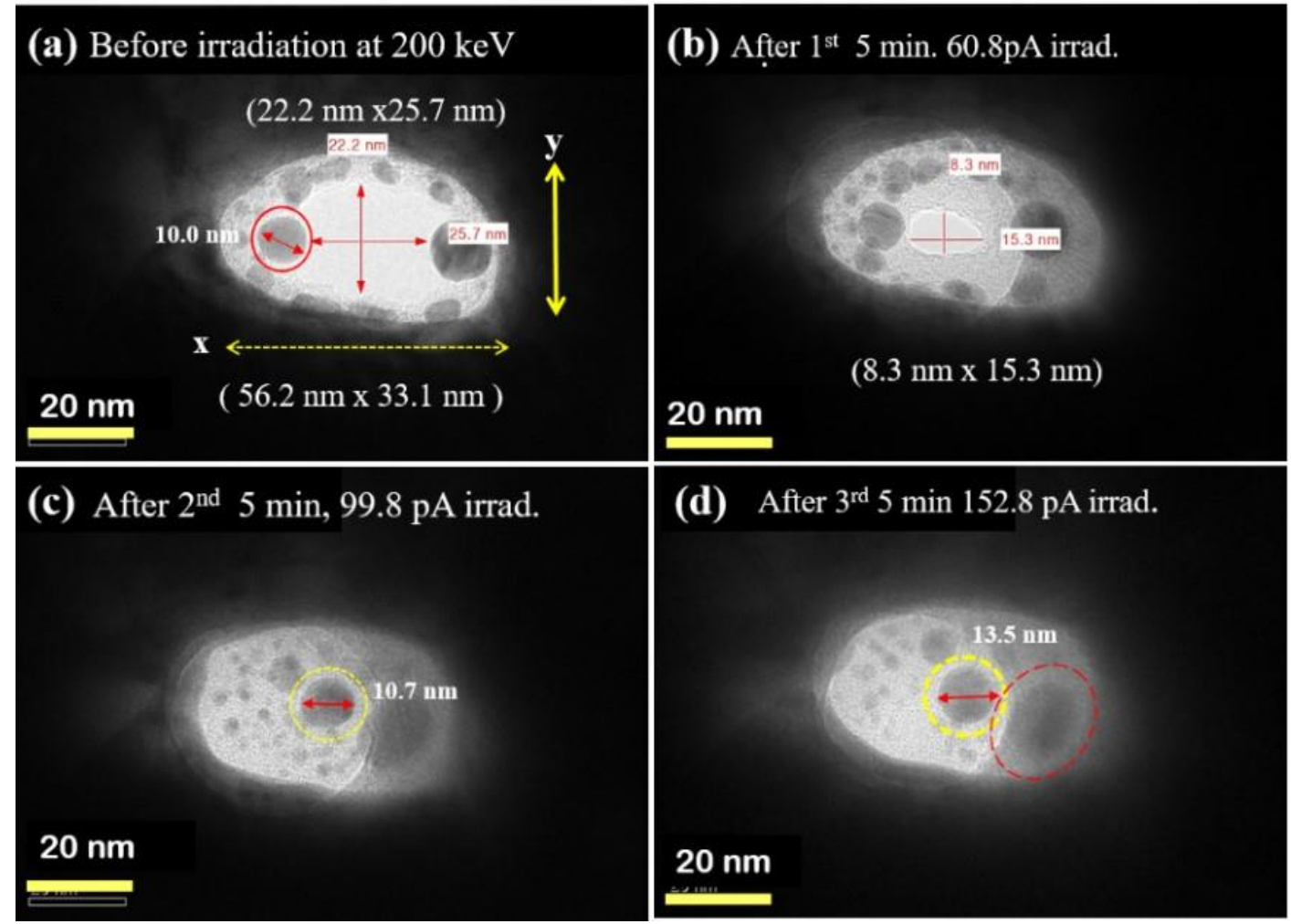

Figure 4 TEM images of nanopore under high energy electron currents at $200 \mathrm{keV}$ (JEM2010). A (56.2 nm x $33.1 \mathrm{~nm}$ ) size Au aperture before irradiation (a), Reduced nanopore of $(8.3 \mathrm{~nm} \times 15.3 \mathrm{~nm})$ under $1 \mathrm{st} 60.8 \mathrm{pA} / \mathrm{cm}^{2}$ electron beam irradiation (b), a completely closed pore under 2nd $99.8 \mathrm{pA} / \mathrm{cm}^{2}$ electron beam irradiation (c), thinned pore membrane under the very high intensity $152.8 \mathrm{pA} / \mathrm{cm}^{2}$ for 5 -minute irradiation (d). Several Au nanoparticles evaporated and became smaller along with thinning of the membrane, (c) and (d). Diffusion of $10 \mathrm{~nm}$ size Au nanoparticle under $60.8 \mathrm{pA} / \mathrm{cm}^{2}$ electron beam irradiation, (b) and (c).

\subsection{Optical Characteristics for the Fabricated Nano-Aperture Platforms: Nano-Slits Array and Nanopores on Pyramid}

\subsubsection{Nanoslit Array on $\sim 130 \mathrm{~nm}$ Thick Au Film with Various Slit Sizes}

Four different types of optical platforms are fabricated on $\sim 130 \mathrm{~nm}$ Au film as in Figure 5; a (7x 7) circular type aperture array with a $100 \mathrm{~nm}$ designed diameter, two $(7 \times 7)$ slit arrays with a (100 $\mathrm{nm}$ wide $\times 500 \mathrm{~nm}$ long) slit size, $(7 \times 7)$ slit array with a ( $\sim 0 \mathrm{~nm}$ wide $\times 500 \mathrm{~nm}$ long) slit size. The $(x, y)$ pitch of the circular type aperture and the slit array are designed as $(1 \mu \mathrm{m}, 1 \mu \mathrm{m})$ and $(550 \mathrm{~nm}$, $500 \mathrm{~nm}$ ), respectively, in Figure 5(a) and Figure 5(b). The measured pitches for the slit array pitch are ( $\sim 532 \mathrm{~nm}, \sim 471 \mathrm{~nm}$ ), in Figure $5(\mathrm{~b})$. The ( $\sim 40 \mathrm{~nm}$ wide $\mathrm{x} \sim 500 \mathrm{~nm}$ long) slit with tiny Au clusters and particles on the diffused membrane formed during $\mathrm{Ga}$ ion beam milling is also shown in Figure 5(c). The corresponding electronic profile for the width of the slit is in Figure 5(d). 


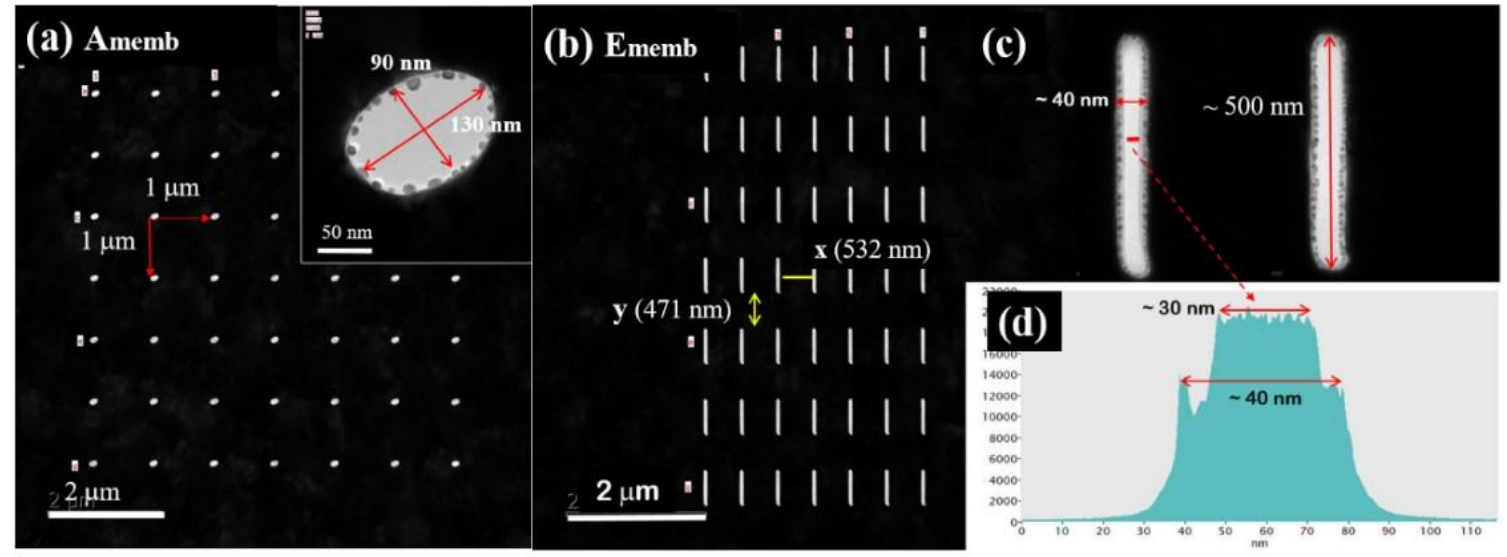

Figure 5 TEM images of the circular type aperture with a size of $(130 \mathrm{~nm} \times 90 \mathrm{~nm})$ and a nanoscale slit array ( $\sim 40 \mathrm{~nm}$ wide $x \sim 500 \mathrm{~nm}$ long). The $(x, y)$ pitches of the $(7 \times 7)$ circular type array and $(7 \times 7)$ nanoslit array are $(\sim 1 \mu \mathrm{m} \times 1 \mu \mathrm{m})$ and (532 nm $\times 471 \mathrm{~nm})$, respectively. The TEM image of the nanoslit and the corresponding electronic profiles:

(c) and (d).

Figure 6 presents the optical emission profiles from 4 nanoaperture platforms. All four nanoapertures have sharp optical spectra centered at $\sim 500 \mathrm{~nm}$, possibly due to the SPP-mediated intraband emission. The two $(7 \times 7)$ nanoslit arrays with $100 \mathrm{~nm}$ widths (G membrane and $\mathrm{H}$ membrane) present identical small SPP-coupled_transmission peaks centered at $671.5 \mathrm{~nm}$. However, the nanoslit array with $\sim 40 \mathrm{~nm}$ width ( $\mathrm{F}$ membrane) presents a smaller shoulder profile at $665 \mathrm{~nm}$ than those from ( $G$ and $H$ ). Moreover, the optical emission profile from $A$ membrane with a $(7 \times 7)$ circular type array with a ( $130 \mathrm{~nm} \times 90 \mathrm{~nm})$ aperture size presents a sharp emission peak at $\sim 500 \mathrm{~nm}$ with a negligible shoulder at $\sim 650 \mathrm{~nm}$.

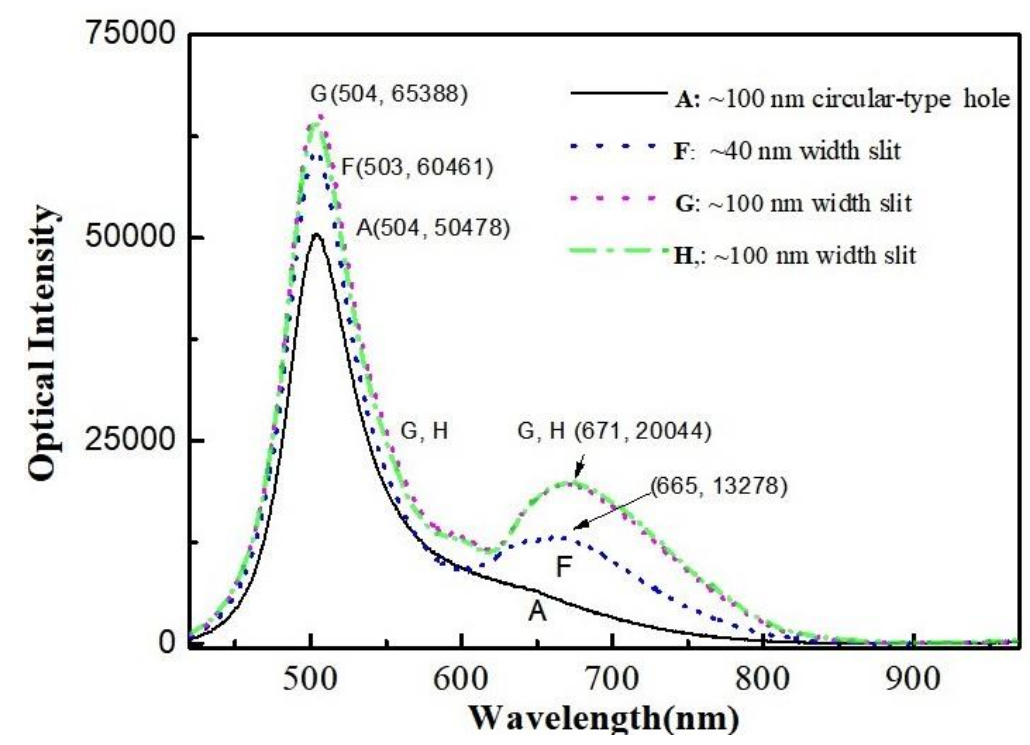

Figure 6 Optical characteristics of the $(7 \times 7)$ nanoslit array. A solid black line (A: a $(7 \times 7)$ circular type aperture array with a single aperture size of ( $130 \mathrm{~nm} \times \sim 90 \mathrm{~nm})$ ), a dotted blue line (F: slit size with $500 \mathrm{~nm}$ long and $40 \mathrm{~nm}$ wide), a red dash-dot red line (G: slit size with $500 \mathrm{~nm}$ long and $100 \mathrm{~nm}$ wide), and a green dash-dotted line (H: $500 \mathrm{~nm}$ long and $100 \mathrm{~nm}$ wide) 


\subsubsection{Nanopores on Pyramids with $\sim 10^{2} \mathrm{~nm}$ Aperture sizes}

The nanoapertures on a pyramidal array are fabricated using Si microfabrication technique followed by metal deposition as in Figure 1. 5 TEM images are shown in Figure 7. In the dashed yellow circles in Figure 7(a) and 7(b), and a red dotted circle in Figure 7(c), the white area indicates an optically transparent nanopore region. The formed nanopores of the samples a3, a4, and a12 are measured to be $(23 \mathrm{~nm} \times 18 \mathrm{~nm}),(62 \mathrm{~nm} \times 42 \mathrm{~nm}),(26.1 \mathrm{~nm} \times 43.5 \mathrm{~nm})$ on the thin membrane inside the apertures of $(86.7 \mathrm{~nm} \times 143 \mathrm{~nm}),(83.6 \mathrm{~nm} \times 97.1 \mathrm{~nm})$, and $(111.8 \mathrm{~nm} \times 152.7 \mathrm{~nm})$, respectively. The nanoapertures of sample a15 and sample a19 are measured to be (112.5 nm x $130.4 \mathrm{~nm})$, and $(212.0 \mathrm{~nm} \times 134.0 \mathrm{~nm})$, respectively. The dark spots around the circumference of the aperture in Figure 7(a)-Figure 7(d) are Au clusters and numerous Au tiny particles (in the gray area in Figure 7(e)). The formation of $\mathrm{Au}$ nanoparticles and Au clusters on the gray membrane areas can be attributed to thermal spike during FIB drilling, and can also contribute to enhanced optical emission.
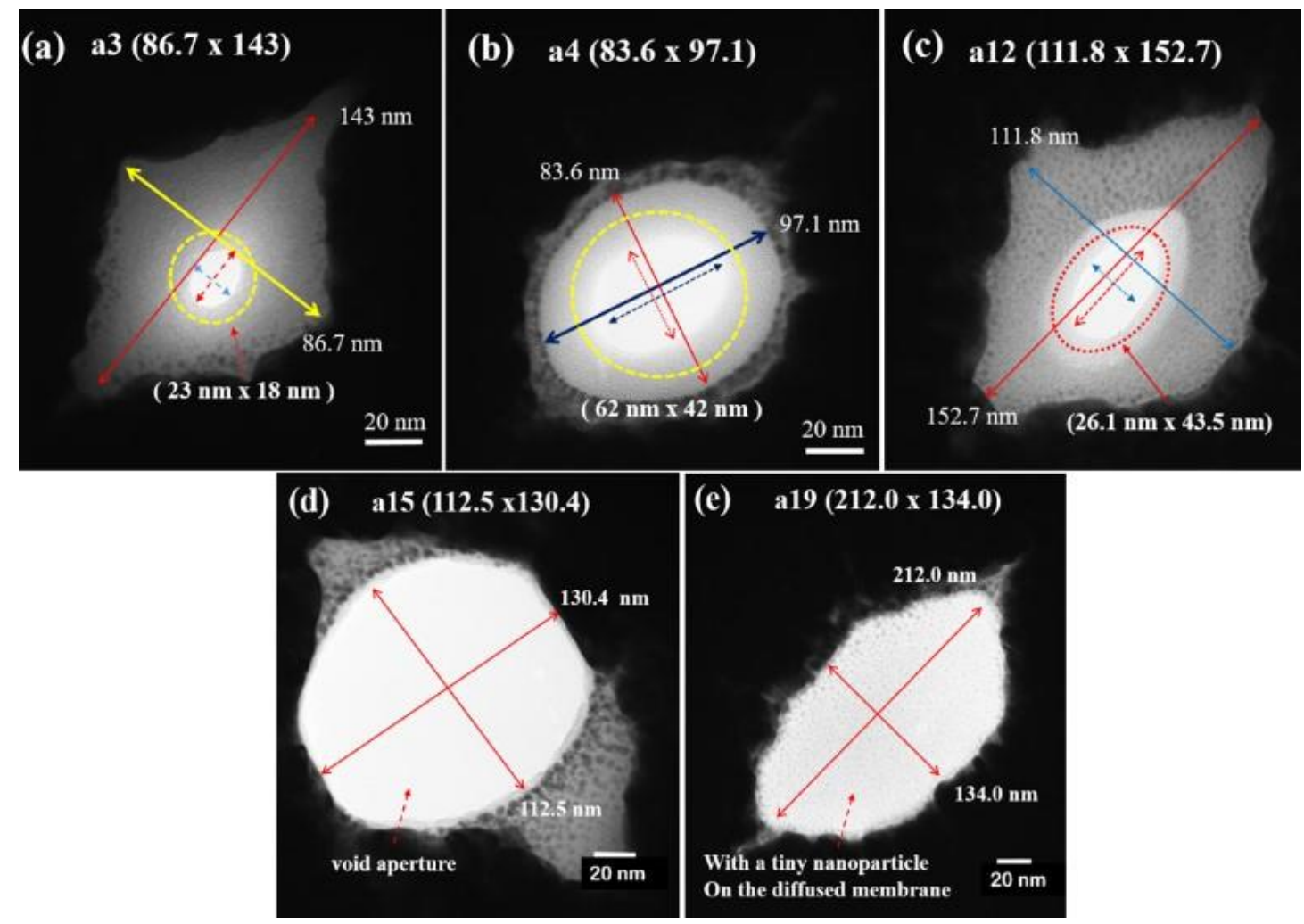

Figure 7 TEM images of nanopores and nanoapertures on pyramidal apices with a 200 $\mathrm{nm}$ thick Au film. The white pore areas inside the dotted circular gray area membrane are presented in (a), (b), and (c). The pore areas of a3, a4, and a12 are ( $23 \mathrm{~nm} \times 18 \mathrm{~nm})$, $(62 \mathrm{~nm} \times 42 \mathrm{~nm})$, and $(26.1 \mathrm{~nm} \times 43.5 \mathrm{~nm})$, respectively. The nanoapertures with sizes $(112.5 \mathrm{~nm} \times 130.4 \mathrm{~nm})$ and $(212.0 \mathrm{~nm} \times 134.0 \mathrm{~nm})$ are shown in (d) and (e), respectively. The diffused gray areas are the thin membranes composed of gold and carbon atoms in (d). Additionally, the tiny Au particles and clusters are present in the diffused dark gray area. However, the white aperture area also consists of small Au nanoparticles on the diffused thin membrane in panel (e). 
Table 1 presents the optical output intensity against wavelengths by using a solid-state Nd:YAG laser system with a wavelength of $532 \mathrm{~nm}$ as a light source and a silicon photosensor with a $15 \mathrm{~mm}$ cone attenuated F filter (spectral range: $400 \mathrm{~nm} \sim 1064 \mathrm{~nm}$ ) for photodetection using a Witec SNOM instrument. For the $532 \mathrm{~nm}$ input wavelength, the output intensities through the nanoapertures of samples a3, a4, a15, and a19 vary from $38.6 \mathrm{~W}$ to $48.3 \mathrm{~W}$. The ratios for the samples a3, a4, a15, and a19 are of the order of $\sim 3.1 \times 10^{-2}, 3.1 \times 10^{-2}, 2.6 \times 10^{-2}, 3.3 \times 10^{-2}$, respectively. For $780 \mathrm{~nm}$ input wavelength, the output intensities through the nanoapertures of samples a3, a4, a15, and a19 are measured to be $8.4 \mathrm{~W}, 7.7 \mathrm{~W}, 6.7 \mathrm{~W}, 14.3 \mathrm{~W}$, respectively, and the corresponding ratios are $0.36 \mathrm{x}$ $10^{-2}, 0.33 \times 10^{-2}, 0.28 \times 10^{-2}$, and $0.60 \times 10^{-2}$, respectively. These differences are attributed to higher excitation of photons at $532 \mathrm{~nm}$ input wavelength than at $780 \mathrm{~nm}$ and to the SPP-mediated emission peak at $\sim 500 \mathrm{~nm}$.

Table 1 Optical characteristics of the fabricated Au nanoapertures with sizes of a3 ( 143 $\mathrm{nm} x \sim 86.7 \mathrm{~nm}), \mathrm{a} 4(\sim 83.6 \mathrm{~nm} \mathrm{x} \sim 97.1 \mathrm{~nm})$, a15 ( 112.5 nm x $130.4 \mathrm{~nm})$, and a19 $(134.0 \mathrm{~nm} \times 212.0 \mathrm{~nm})$ are presented for the input wavelengths of $532 \mathrm{~nm}$ and $780 \mathrm{~nm}$.

\begin{tabular}{cccccc}
\hline $\begin{array}{c}\text { Sample } \\
\text { ID }\end{array}$ & $\begin{array}{c}\text { aperture size } \\
\left(\mathrm{nm}^{2}\right)\end{array}$ & $\begin{array}{c}\text { Input wavelength } \\
(\mathrm{nm})\end{array}$ & $\begin{array}{c}\text { Input Intensity } \\
\left(\mu \mathrm{W} / \mathrm{cm}^{2}\right)\end{array}$ & $\begin{array}{c}\text { Output Intensity } \\
\left(\mu \mathrm{W} / \mathrm{cm}^{2}\right)\end{array}$ & $\begin{array}{c}\text { Iout }_{\text {lin }} \\
\left(\times 10^{-2}\right)\end{array}$ \\
\hline a3 & $143 \times 86.7$ & & & 45.7 & 3.1 \\
a4 & $83.6 \times 97.1$ & 532 & 1477 & 42.0 & 3.1 \\
a15 & $112.5 \times 130.4$ & & & 38.6 & 2.6 \\
a19 & $134.0 \times 212.0$ & & & 48.3 & 3.3 \\
\hline a3 & $143 \times 86.7$ & & 8.4 & 0.36 \\
a4 & $83.6 \times 97.1$ & 780 & 2366 & 7.7 & 0.33 \\
a15 & $112.5 \times 130.4$ & & & 6.7 & 0.28 \\
a19 & $134.0 \times 212.0$ & & & 14.3 & 0.60 \\
\hline
\end{tabular}

The optical output intensity versus wavelength for samples a3, a4, a15, and a19 are presented in Figure 8. Optical characterization was performed using a Nikon Optical Eclipse Ti-U microscope with Princeton Instruments spectrophotometer (Acton SpectroPro 2300i, $150 \mathrm{~g} / \mathrm{mm}$ ) [Figure S2]. Input optical Gaussian beam intensity was calibrated using a $(17 \mu \mathrm{m} \times 17 \mu \mathrm{m})$ square Si aperture. Output beam intensity profiles from sample a3 and sample a4 are presented in Figure 8(a). The areas of these particular samples of a3 and a4 are very close to each other, $7820 \mathrm{~nm}^{2}$ and $6680 \mathrm{~nm}^{2}$, respectively, and the ratio versus wavelength optical spectra are precise. Additionally, even with the $532 \mathrm{~nm}$ wavelength laser measurements, the ratios of the output to the input intensity are also the same; $3.1 \times 10^{-2}$. We observed the similar results from the sample a12, and a14 [Figure S3]. Two optical beam profiles have optical peaks at $568 \mathrm{~nm}$ and two inflection points- one at $511.8 \mathrm{~nm}$ and another at $675.2 \mathrm{~nm}$. The point of inflection at $511.8 \mathrm{~nm}$ may be attributed to the intraband transition emission, and the point of inflection at $675.2 \mathrm{~nm}$ could be attributed to SPP-coupled incoming wave via nanoaperture. For sample a19, shown in Figure 8(b), the output optical peak 
$\sim 595.8 \mathrm{~nm}$ with a broadened Gaussian shape between $\sim 500 \mathrm{~nm}$ and $\sim 700 \mathrm{~nm}$ are presented. The optical profile of sample a15, given in Figure $8(\mathrm{~b})$, has a center point at $607.8 \mathrm{~nm}$ with broadband between $\sim 524.8 \mathrm{~nm}$ and $\sim 691.9 \mathrm{~nm}$. Optical profile broadening with increased aperture size is agreeable with the previously published results [31, 32]. The SPP-coupled intraband optical emission would increase with the decreasing aperture diameter and the increasing surface wave along the pyramidal surfaces emanated from the aperture on the pyramidal apex.
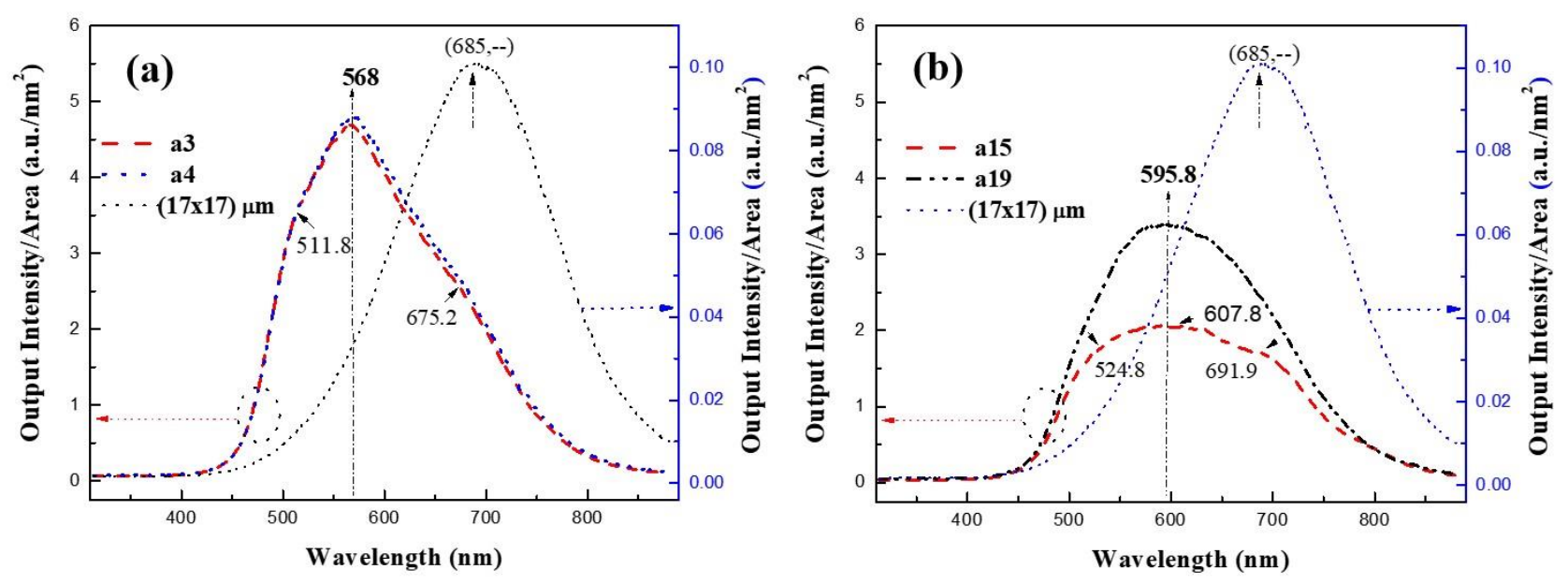

Figure 8 Normalized output optical intensities for Au apertures with optical Gaussian peaks at $\sim 685 \mathrm{~nm}$. For the $\mathrm{Au}$ apertures of a3 and a4 samples, the output spectra centered at $\sim 568 \mathrm{~nm}$ and $\sim 569 \mathrm{~nm}$ along with relatively sharp and narrow Gaussian-type shape spectra (a). Both transmitted optical profiles of sample a3 and sample a4 have optical peaks at $\sim 568 \mathrm{~nm}$ with two points of inflection- one at $\sim 511.8 \mathrm{~nm}$ and the other at $\sim 675.2 \mathrm{~nm}$. For a19 sample (b), the output optical peak is at $\sim 595.8 \mathrm{~nm}$ with a broadened Gaussian shape between $\sim 500 \mathrm{~nm}$ and $\sim 700 \mathrm{~nm}$. For sample a15, the profile has a center at $\sim 607.8 \mathrm{~nm}$ with broadband between $\sim 524.8 \mathrm{~nm}$ and $\sim 691.9 \mathrm{~nm}$. Input beam optical intensity was calibrated using $(17 \mu \mathrm{m} \times 17 \mu \mathrm{m})$ aperture.

The ratio of output intensity to input intensity can provide information on the nanoapertures and their optical characteristics. Figure 9 presents the graph of the ratio of normalized output intensity to normalized input intensity versus wavelength. The sharp conical ratio profiles with the optical peaks at $497 \mathrm{~nm}$ and $499 \mathrm{~nm}$ for the sample a3 and a4 respectively are shown with slightly deviated to the right wavelength from the peak line at $497 \mathrm{~nm}$. The asymmetrical profile presents: at the ratio value of 150 , close to the half maximum, the corresponding wavelengths are $467.6 \mathrm{~nm}$ and $551.1 \mathrm{~nm}$, not symmetrical from the peak. For samples a15 and a19, the profiles became broader and asymmetrical with a peak at $\sim 500 \mathrm{~nm}$. The contribution from the SPP-coupled wave with the incoming beam through the aperture may cause this asymmetrical profile. 


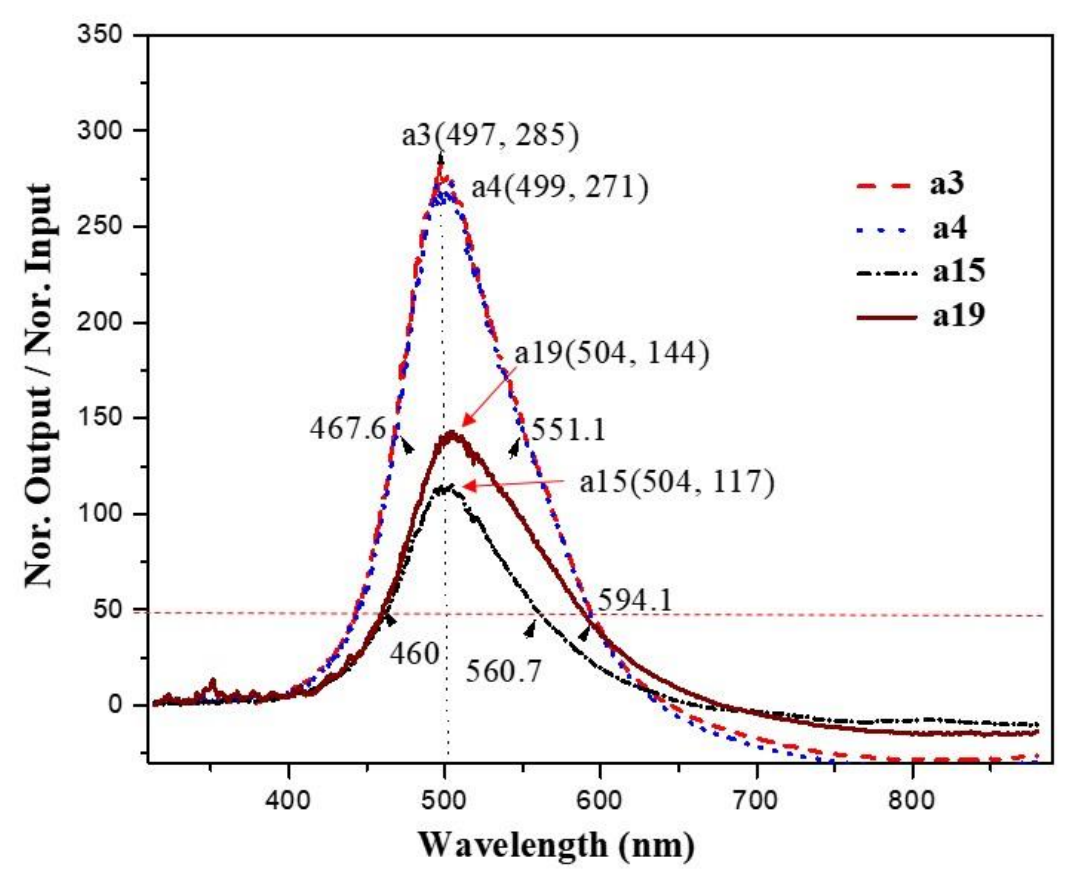

Figure 9 Plot of the ratio of normalized output intensity to normalized input intensity versus wavelength for samples a3, a4, a15, and a19. For samples a3 and a4, the ratio profiles present a conical shape centered at $\sim 497 \mathrm{~nm}$ and $\sim 499 \mathrm{~nm}$, respectively. For samples a15 and a19, the ratio profiles are lower maxima with a greater full width half maximum (FWHM) than with a3 and a4 samples.

\subsubsection{Fabrication of $(7 \times 7)$ Nanoslit Array with a $(10 \mathrm{~nm} \times \sim 300 \mathrm{~nm})$ Slit Size}

We fabricated the $(7 \times 7)$ nanoslit arrays using $30 \mathrm{keV} \mathrm{Ga}$ ion FIB on the $200 \mathrm{~nm}$ thick Au on the supporting layer $20 \mathrm{~nm}$ SiN. Figure 10 (a) presents TEM images of the ( 100 $\mu \mathrm{m} x \sim 100 \mu \mathrm{m}) \mathrm{m}$ membrane and the $(7 \times 7)$ nanoslit array with a $(\sim 3 \mu \mathrm{m} x \sim 3 \mu \mathrm{m})$ size at the center of the $A, C, E$, and $F$ membranes (inside a solid yellow circle). The $(x, y)$ pitch is measured to be $(500 \mathrm{~nm}, 250 \mathrm{~nm})$ in Figure 10(c) and Figure 10(d). The size of each nanoslit is measured to be ( $10 \mathrm{~nm} x \sim 300 \mathrm{~nm})$. Figure 11 presents the TEM images of the slits with $10 \mathrm{~nm}$ opening on the A membrane. TEM images for the $E$ membrane are shown [Figure S3]. A FESEM image of an $\sim 200 \mathrm{~nm}$ size Au particle on the C membrane and a TEM image of the $(\sim 7.2 \mu \mathrm{m} x \sim 2.3 \mu \mathrm{m})$ size aperture on the F membrane are presented [Figure S4]. Figure 12 exhibits the measured optical characteristics for the four samples. The optical spectra ranging from $\sim 450 \mathrm{~nm}$ to $\sim 900 \mathrm{~nm}$ are shown along with small Gaussian shape emission peaks at $\sim 500 \mathrm{~nm}$. Two broad emission bands from sample $A$ and sample $E$ exhibit relatively flat broad bands with a plateau region from $\sim 600 \mathrm{~nm}$ to $\sim 850 \mathrm{~nm}$. However, the emission band from $E$ has greater intensities by double than those from sample $A$. The difference can be attributed to the different surface statuses between the two samples. The green strong peak at $F$ (665.8) may be attributed to the SPP-coupling contribution from the small void aperture $(\sim 7.2 \mu \mathrm{m} \mathrm{x}$ $\sim 2.3 \mu \mathrm{m}$ ) on the membrane. A red sharp infrared peak at $C$ (769.1) can be attributed to the SPPscattering from a $200 \mathrm{~nm}$ size Au particle. 

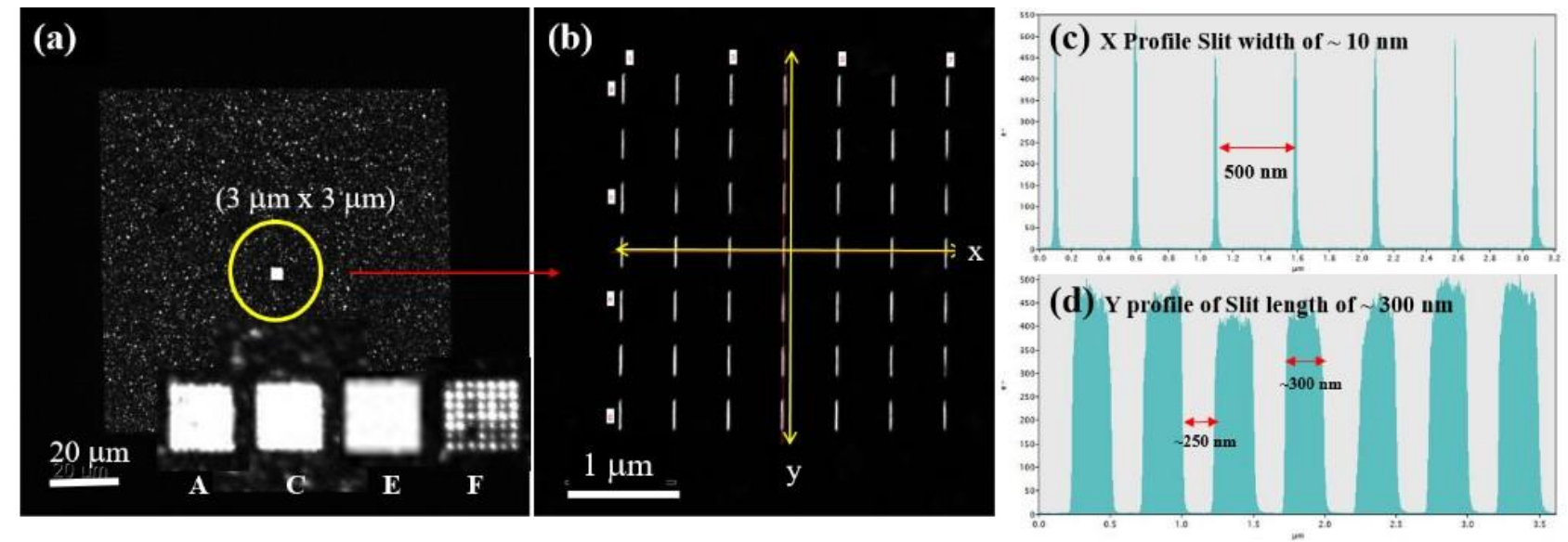

Figure 10 TEM images of the $(\sim 100 \mu \mathrm{m} \times \sim 100 \mu \mathrm{m})$ membrane and the $(7 \times 7)$ nanoslit array with ( $\sim 3 \mu \mathrm{m} \times \sim 3 \mu \mathrm{m})$ at the center of the $A, C, E$, and $F$ membrane (inside a solid yellow circle). The three white squares at the bottom indicate the nanoslit areas of $A, C$, and $E$ membranes, and the gray square area with grids indicates the nanoslit in the $F$ membrane. The $(x, y)$ profiles at the electron beam detector were measured. The widths and the length of the slits are found to be $\sim 10 \mathrm{~nm}$ and $\sim 300 \mathrm{~nm}$, respectively. The $(x, y)$ pitches of the slit arrays are found to be $(\sim 500 \mathrm{~nm}, \sim 250 \mathrm{~nm})$ in (c) and (d).
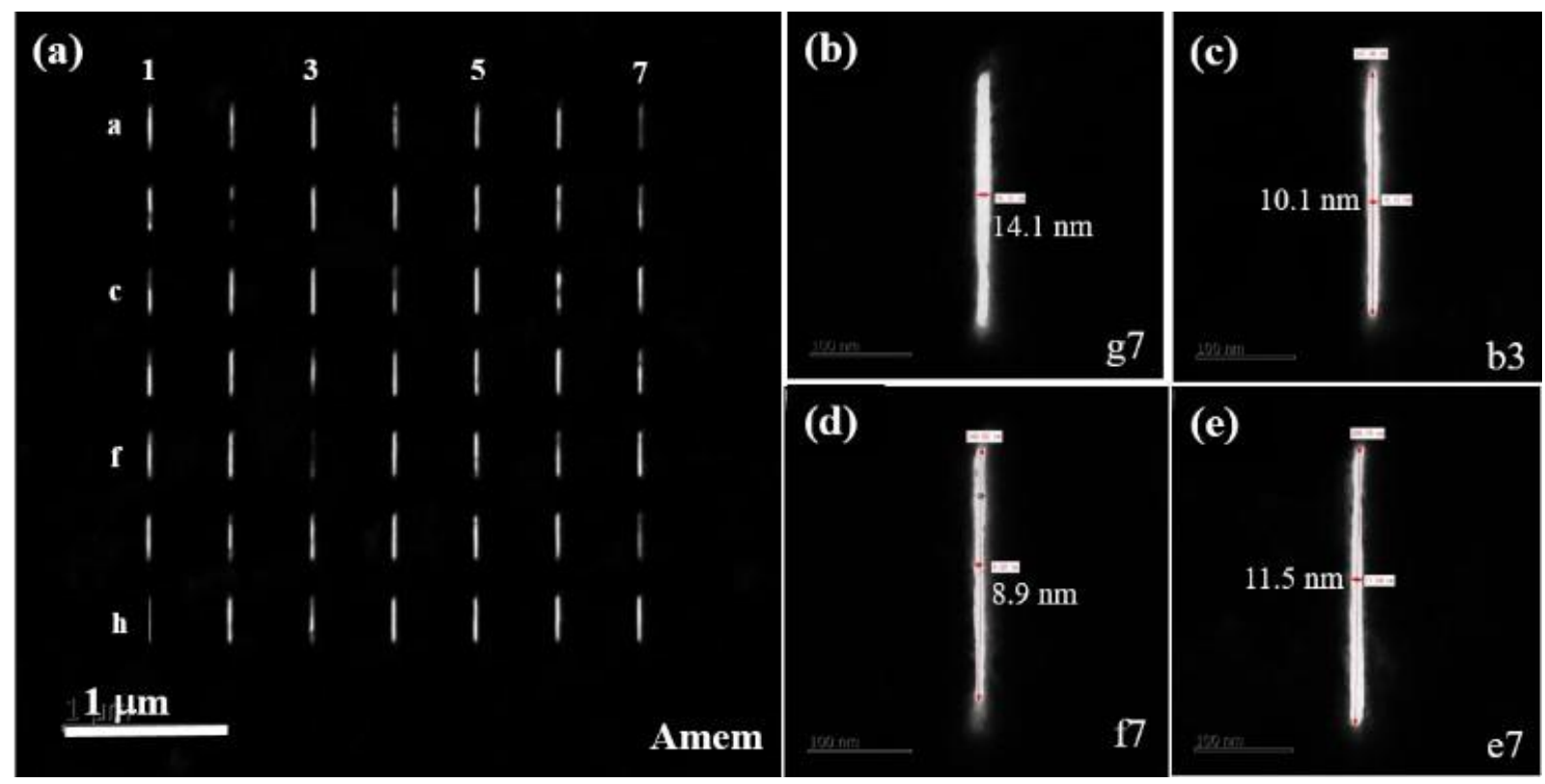

Figure 11 TEM images of sample A membrane for a $(7 \times 7)$ nanoslit array. Several dim nanoslits are also shown due to the diffusion of Au atoms during $30 \mathrm{keV} \mathrm{Ga}$ ion beam drilling. The slit widths of ( $\mathrm{g} 7, \mathrm{b3}, \mathrm{f7}$, and e7) are measured to be $14.1 \mathrm{~nm}, 10.1 \mathrm{~nm}, 8.9$ $\mathrm{nm}$, and $11.5 \mathrm{~nm}$, respectively. 


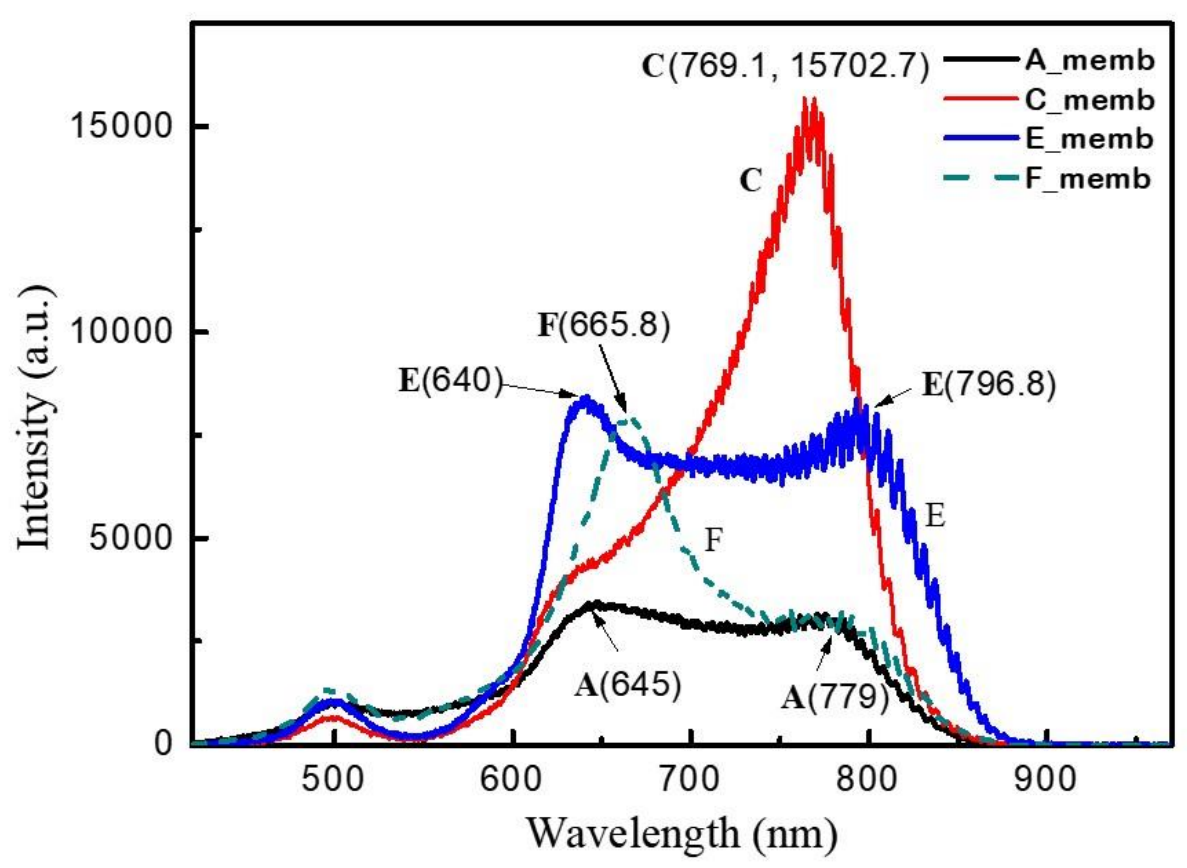

Figure 12 Optical characteristics of the $(7 \times 7)$ slit arrays. Optical emission spectra ranging from $\sim 450 \mathrm{~nm}$ to $\sim 900 \mathrm{~nm}$ with a small emission peak at $\sim 500 \mathrm{~nm}$. Two optical emission spectra from sample $A$ and sample $E$ present relatively flat broad bands (plateau region) from $\sim 640 \mathrm{~nm}$ to $\sim 800 \mathrm{~nm}$. A strong emission peak at $665.8 \mathrm{~nm}$ from sample $F$ (blue line) and a sharp peak at $769.1 \mathrm{~nm}$ from sample $C$ (red line) can be attributed to the contribution from the beam transmitted through the hole on the $F$ membrane and scattering from $\sim 200 \mathrm{~nm}$ Au particle on the $\mathrm{C}$ membrane, respectively.

\section{Discussion}

(i) We investigated the influence of high-energy electron beam irradiation dependent on the aperture size. We performed two-step electron beam irradiations for the aperture greater than its thickness: 2 keV FESEM electron beam irradiation followed by electron beam irradiation at 3 pA, $300 \mathrm{keV}$ TEM to obtain a nanopore of $\sim 4 \mathrm{~nm}$ on the $\sim 279.5 \mathrm{~nm}$ diameter Au aperture. For the apertures smaller than aperture thickness, higher electron beam currents of $\sim 60 \mathrm{pA}$ or more at 200 $\mathrm{keV}$ TEM were irradiated on the $(56.2 \mathrm{~nm} \times 33.1 \mathrm{~nm})$ Au aperture on the $200 \mathrm{~nm}$ thick Au film to obtain the Au nanopore with its size of $(8.3 \mathrm{~nm} \times 15.3 \mathrm{~nm})$. With the currents higher than $100 \mathrm{pA}$ at $200 \mathrm{keV}$, pore closing and thinning of the formed membrane are observed due to diffusion of gold atoms and carbon atoms, sputtering of carbon atoms, and evaporation of Au atoms.

(ii) Au nanopores and apertures on the pyramidal apices with optical characterizations: Au pyramidal-apertures with sizes ranging from (143 nm x $86.7 \mathrm{~nm})$ to $(134 \mathrm{~nm} \times 212 \mathrm{~nm}$ ) were microfabricated). The observed output intensity peaks for the relatively small aperture areas of a3 (143 $\mathrm{nm} \times 86.7 \mathrm{~nm})$ and a4 $(83.6 \mathrm{~nm} \times 97.1 \mathrm{~nm})$ and for the larger areas of the samples a15 $(112.5 \times 130.4$ $\mathrm{nm})$ and a19 (134.0 nm $\times 212.0 \mathrm{~nm}$ ) are observed to be at $568.2 \mathrm{~nm}$ and $569.2 \mathrm{~nm}$, and $596.5 \mathrm{~nm}$ and $592.7 \mathrm{~nm}$, respectively. The Full Width Half Maxima (FWHM) for the optical spectra from the a3 sample and the a4 sample is much narrower than those for sample a15 and sample 19. The greater FWHM with the shifted peak to the higher wavelengths indicates the coupling with the incoming 
wave. Additionally, the ratio profiles also present a strong contribution from the SPP-mediated intraband emission at $\sim 500 \mathrm{~nm}$. The precise optical emission spectra along with the ratio profiles from sample a3 and the sample a4 can be attributed to Lord Raleigh's statement about the diffraction small particle and Babinet principle; the far-field emission does not depend upon the shape of the particle and the aperture for the small particle and aperture smaller than the wavelength. Moreover, optical profile broadening with increased aperture size is agreeable with the previously published results by Obermüller et al. With decreasing the aperture diameter, the increased SPP-coupled intraband optical emission is observed due to the increased surface wave along the pyramidal surfaces emanated from the aperture on the pyramidal apex. For the small apertures of the sample a3 and the sample a4, the conical type output optical profiles are shown with a peak at $568 \mathrm{~nm}$; however, for the larger apertures of the sample a15 and the sample a19, the broad profiles are shown with the shifted peak position at $595.8 \mathrm{~nm}$ from input peak at $685 \mathrm{~nm}$. The peak shift can be attributed to SPP-coupling from incoming optical beam through the nanoapertures and the possible scattering with Au particles and Au clusters. The detailed physical mechanism should be investigated further.

(iii) Optical characterization of the fabricated platforms with a $(7 \times 7)$ nanoslit array, or with a circular type hole array with a $(90 \mathrm{~nm} \times 130 \mathrm{~nm})$ size on the $130 \mathrm{~nm}$ thick Au film: Regardless of the aperture types, either circular or slit, sharp optical peaks at $\sim 500 \mathrm{~nm}$ are observed. For the nanoslit array with a slit dimension of ( $\sim 100 \mathrm{~nm} \times \sim 500 \mathrm{~nm}$ ), a sharp conical type profile with its peak at $\sim 500$ $\mathrm{nm}$ and a broad profile with a small peak at $\sim 671 \mathrm{~nm}$ are observed. Even though a sharp conicalshaped profile with a peak at $\sim 500 \mathrm{~nm}$ is observed for the nanoslit array with a slit dimension of ( $\sim 40 \mathrm{~nm} x \sim 500 \mathrm{~nm})$, a smaller broad profile at $665 \mathrm{~nm}$ is also seen. No optical emission peak at $\sim 670$ $\mathrm{nm}$ is observed for this sample and a $(7 \times 7)$ circular type hole array with ( $90 \mathrm{~nm} \times 130 \mathrm{~nm}$ ) dimensions on the $\sim 130 \mathrm{~nm}$ thick Au membrane.

(iv) The broad optical spectra ranging from $550 \mathrm{~nm}$ to $900 \mathrm{~nm}$ with a small optical peak at 500 $\mathrm{nm}$ were obtained from the $(7 \times 7)$ nanoslit array platforms, possibly contributed from the SPPmediated intraband emission. The fabricated $(7 \times 7)$ nanoslit array consists of each slit with ( $10 \mathrm{~nm}$ $x \sim 300 \mathrm{~nm})$ dimensions. The $(x, y)$ pitch of the slit array is estimated to be $(250 \mathrm{~nm}, 500 \mathrm{~nm})$. The small optical peak at $500 \mathrm{~nm}$ can be attributed to the SPP-mediated intraband emission. The broad emission in the visible range can be due to the interband transitions of $d$-band electrons into the conduction band, and the emission in the infrared region is generated from the intraband transitions mediated by the strongly confined fields (localized surface plasmons) from the nanoslit array with $\sim 10 \mathrm{~nm}$ slit opening.

\section{Conclusions}

We conclude the following:

(i) Depending on the aperture thickness and aperture diameter, pore-formation procedures should be varied.

(ii) Optical emission characteristics from various Au nanostructures are dependent on the film thickness and aperture size.

(iii) A strong contribution from SPP-mediated intraband for small apertures and a weak contribution from SPP-coupled transition for larger apertures are observed. 


\section{Acknowledgments}

This work was supported by the research funding programs (Development of Biofriendly Optical Nanopore, 2018R1D1A1B07050106) under the Basic Science Research Program through the National Research Foundation (NRF) funded by the Ministry of Education, Science and Technology, South Korea.

\section{Additional Materials}

The following additional materials are uploaded at the page of this paper.

1. Figure S1: The following schematic diagram show the optical systems using 532 laser and Halogen lamp.

2. Figure S2: Pyramidal apertures with the a3 and a4, with a12 and a14.

3. Figure S3: (7x7) slit array Ememb.

4. Figure S4: FESEM image of an $\sim 200 \mathrm{~nm}$ diameter Au nanoparticle on C membrane (left) and TEM image of a void aperture of $(7.2 \mu \mathrm{m} \times 2.3 \mu \mathrm{m})$ size on the $\mathrm{F}$ membrane (right).

\section{Author Contributions}

Conceptualization, Choi, S.S. (nanofabrication); Kim, K.J. (single molecule detection); Park, M.J. (plasmonics); methodology, Bae B.S. (materials preparation); Kim, H.T.; Choi, S.B.; formal analysis, Choi, S.S.; Kim, H.T.; investigation, Choi, S.S.; resources; data curation, Bae B.S., Lee Y.M.; writingoriginal draft preparation, Choi, S.S.; writing—review and editing, Bae, B.S.; Park, M.J.; Lee, Y.M.

\section{Funding}

This work was supported by the research funding programs (Development of Biofriendly Optical Nanopore, 2018R1D1A1B07050106) under the Basic Science Research Program through the National Research Foundation (NRF) funded by the Ministry of Education, Science and Technology, South Korea.

\section{Competing Interests}

The authors have declared that no competing interests exist.

\section{References}

1. Howorka S, Cheley S, Bayley H. Sequence-specific detection of individual DNA strands using engineered nanopore. Nat Biotechnol. 2001; 19: 636-639.

2. Ebbesen TW, Lezec HJ, Ghaemi HF, Thio T, Wolff PA. Extraordinary optical transmission through sub-wavelength hole arrays. Nature. 1998; 391: 667-669.

3. Choi SS, Park MJ, Han CH, Oh SJ, Han SH, Park NK, et al. Fabrication of pyramidal probes with various periodic patterns and a single nanopore. J Vac Sci Technol B. 2015; 33: 06F203.

4. Choi SS, Park MJ, Han CH, Oh SJ, Yamaguchi T, Park NK, et al. Formation of an Au membrane incorporated with carbon atoms under electron beam irradiations. Surf Coat Technol. 2016; 306: 113-118. 
5. Choi SS, Park MJ, Yamaguchi T, Han CH, Oh SJ, Kim SI, et al. Nanopore formation on Au coated pyramid under electron beam irradiations (plasmonic nanopore on pyramid). Sens Bio-Sens Res. 2016; 7: 153-161.

6. Choi SS, Park MJ, Yamaguchi T, Kim SI, Park KJ, Park NK. Fabrication of nanopore on pyramid. Appl Surf Sci. 2014; 310: 196-203.

7. Choi SS, Oh SJ, Han CH, Park DJ, Choi SB, Kim YS, et al. Au cluster formation on a pore-containing membrane under various surface treatments. J Vac Sci Technol B. 2017; 35: 04F107.

8. Garoli D, Yamazaki H, Maccaferri N, Wanunu M. Plasmonic nanopores for single-molecule detection and manipulation: Toward sequencing applications. Nano Lett. 2019; 19: 7553-7562.

9. Choi SS, Park MJ, Oh SJ, Han CH, Kim YS, Park NK. Plasmonic nanopore with nanopattern and nanoparticles for single molecule analysis. Phys Status Solidi A. 2017; 215: 1700484.

10. Vernon KC, Davis TJ, Scoles FH, Gómez DE, Lau D. Physical mechanisms behind the SERS enhancement of pyramidal pit substrates. J Raman Spectrosc. 2010; 41: 1106-1111.

11. Consoni M, Hazart J, Lérondel G, Vial A. Nanometer scale light focusing with high cavityenhanced output. J Appl Phys. 2009; 105: 084308.

12. Radziuk D, Moehwald H. Prospects for plasmonic hot spots in single molecule SERS towards the chemical imaging of live cells. Phys Chem Chem Phys. 2015; 17: 21072-21093.

13. Bringa EM, Johnson RE. Coulomb explosion and thermal spikes. Phys Rev Lett. 2002; 88: 165501.

14. Howie A. Electron microscopy: Coulomb explosions in metals? Nature. 1986; 320: 684.

15. Martin TP. Shells of atoms. Phys Rep. 1996; 273: 199-241.

16. Komoda T. Study on the structure of evaporated gold particles by means of a high resolution electron microscope. Jpn J Appl Phys. 1968; 7: 27-30.

17. Pashlemy DW, Stowell MJ, Jacobs MH, Law TJ. The growth and structure of gold and silver deposits formed by evaporation inside an electron microscope. Philos Mag. 1964; 10: 127-158.

18. Ino S. Epitaxial growth of metals on rocksalt faces cleaved in vacuum. II. orientation and structure of gold particles formed in ultrahigh vacuum. J Phys Soc Jpn. 1966; 21: 346-362.

19. Buffat Ph, Borel JP. Size effect on the melting temperature of gold particles. Phys Rev A. 1976; 13: 2287-2298.

20. Li H, Li L, Pedersen A, Gao Y, Khetrapal N, Jónsson, H, et al. Magic-number gold nanoclusters with diameters from 1 to $3.5 \mathrm{~nm}$ : Relative stability and catalytic activity for CO oxidation. Nano Lett. 2015; 15: 682-688.

21. Schmidt $M$, Kusche R, von Issendorff $B$, Haberland $H$. Irregular variations in the melting point of size-selected atomic clusters. Nature. 1998; 393: 238-240.

22. Storm AJ, Chen JH, Ling XS, Zanbergen HW, Dekker C. Fabrication of solid-state nanopores with single-nanometre precision. Nat Mater. 2003; 2: 537-540.

23. Li J, Stein D, McMullan C, Branton D, Aziz MJ, Golovchenko JA. Ion-beam sculpting at nanometre length scales. Nature. 2001; 412: 166-169.

24. Trinh TT, Vlugt TJ, Hägg MB, Bedeaux D, Kjelstrup S. Simulation of pore width and pore charge effects on selectivities of $\mathrm{CO}_{2}$ vs. $\mathrm{H}_{2}$ from a syngas-like mixture in carbon mesopores. Energy Procedia. 2015; 64: 150-159.

25. Haque F, Li J, Wu HC, Liang XJ, Guo P. Solid-state and biological nanopore for real-time sensing of single chemical and sequencing of DNA. Nano Today. 2013; 8: 56-74.

26. Schouten HF, Kuzmin N, Dubois G, Visser TD, Gbur G, Alkemade PF, et al. Plasmon-assisted twoslit transmission: Young's experiment revisited. Phys Rev Lett. 2005; 94: 053901. 
27. Gan $\mathrm{CH}, \mathrm{Gbur} \mathrm{G}$, Visser TD. Surface plasmons modulate the spatial coherence in Young's interference experiment. Phys Rev Lett. 2007; 98: 043908.

28. Verma M, Joshi S, Bisht NS, Kandpal HC, Senthilkumaran P, Joseph J. Effect of surface plasmons on spectral switching of polychromatic light with Au-double-slit. J Opt Soc Am A Opt Image Sci Vis. 2012; 29: 195-199.

29. Choi SS, Park MJ, Han CH, Oh SJ, Kim HT, Choi SB, et al. Plasmonic nanopore fabrication for single molecule bio sensor using electron beam irradiation. ECS Trans. 2018; 85: 69-76.

30. Choi SS, Oh SJ, Lee YM, Kim HT, Choi SB, Bae BS. Fabrication of plasmonic optical nanopore platform for single molecule sensing. J Electrochem Soc. 2020; 167: 027503.

31. Choi SS, Park MJ, Lee YM, Bae BS, Kim HT, Choi SB. Fabrication of the Au nano-aperture array platform for single molecule analysis. ECS J Solid State Sci Technol. 2020; 9: 115015.

32. Obermüller C, Karrai K. Far field characterization of diffracting circular apertures. Appl Phys Lett. 1995; 67: 3408-3410.

33. Drezet A, Woehl JC, Huant S. Diffraction by a small aperture in conical geometry: Application to metal-coated tips used in near-field scanning optical microscopy. Phys Rev E. 2002; 65: 046611.

34. Lord Rayleigh FR. XXXVII. On the passage of waves through apertures in plane screens, and allied problems. London Edinburgh Dublin Philos Mag J Sci. 1897; 43: 259-272.

35. Babinet M. Mémoires d'optique météorologique. C R Acad Sci. 1837; 4: 638-648.

36. Gao H, Henzie J, Odom TW. Direct evidence for surface plasmon-mediated enhanced light transmission through metallic nanohole array. Nano Lett. 2006; 6: 2104-2108.

37. Beversluis MR, Bouhelier A, Novotny L. Continuum generation from single gold nanostructures through near-field mediated intraband transitions. Phys Rev B. 2003; 68: 115433.

38. Ebrahimpour Z, Mansour N. Plasmonic near-field effect on visible and near-infrared emissions from self-assembled gold nanoparticle films. Plasmonics. 2018; 13: 1335-1342.

39. Greffet JJ. Revisiting thermal radiation in the near field. C R Phys. 2017; 18: 24-30.

40. Baranov DG, Xiao Y, Nechepurenko IA, Krasnok A, Alù A, Kats MA. Nanophotonic engineering of far-field thermal emitters. Nat Mater. 2019; 8: 920-930.

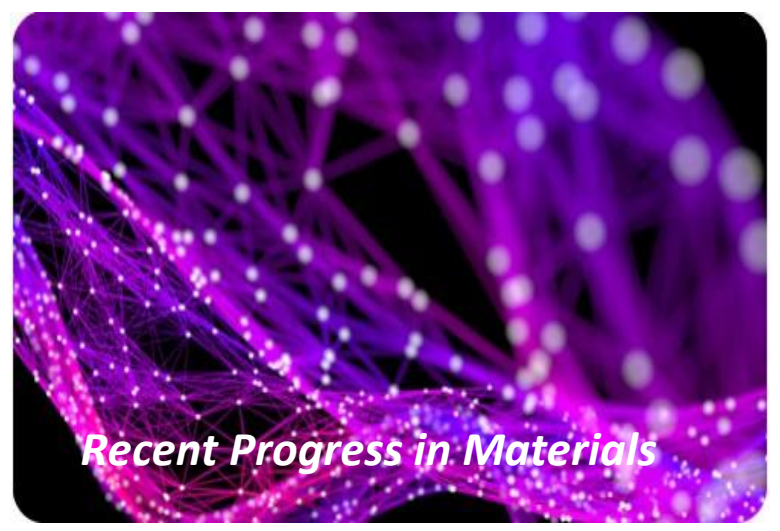

Enjoy Recent Progress in Materials by:

1. Submitting a manuscript

2. Joining in volunteer reviewer bank

3. Joining Editorial Board

4. Guest editing a special issue

For more details, please visit:

http://www.lidsen.com/journals/rpm 